\title{
SURVEY METHODS FOR EUTYPA AND ASSOCIATED WOOD ROTTING FUNGI OF GRAPEVINES
}

\author{
P. JONES ${ }^{1}$, R.E. BRADSHAW ${ }^{1}$ and P.G. LONG $^{2}$ \\ ${ }^{1}$ Institute of Molecular Biosciences, Massey University, Palmerston North \\ ${ }^{2}$ Institute of Natural Resources, Massey University, Palmerston North
}

The first stages in development of a molecular probe for identification of Eutypa lata in grapevine wood have been carried out. DNA has been extracted from pure cultures of the fungus as well as from some other fungi which are commonly found on grapevines. The polymerase chain reaction (PCR) has been used to amplify the ITS region of the ribosomal DNA, a region of the genome expected to be consistent within the species E. lata, whilst being divergent between species. DNA sequence information will be used to design a species-specific molecular probe. The fungus was not consistently isolated from vines with typical symptoms of the disease and results of these attempts to isolate the fungus from diseased vine tissue will be compared with results from attempted identification from the same pieces of tissue using a molecular probe when developed.

\section{CONFOCAL MICROSCOPY OF FUNGAL HYPHAE IN PLANT TISSUE}

\author{
V. VIGNANA SINGHAM and P. G. LONG \\ Institute of Natural Resources, Massey University, Palmerston North
}

The measurement of hyphal volume of plant pathogenic fungi in plant tissue at an early stage of disease development would be useful for infection studies and assessment of the efficacy of biocontrol agents. Fixation of infected plant tissue in glutaraldehyde has been shown to cause fungal hyphae to fluoresce brightly. However, some components of the plant tissue may also fluoresce and cause inaccuracies in measurement of hyphal volumes by confocal laser scanning microscopy. In an earlier study we removed such host fluorescence on each frame of the 3-D image by manually using the paint brush computer programme. This technique was very time consuming and alternative treatment of specimens was investigated. Contrast and resolution of hyphae within host tissue could be improved by: 1) selection of a suitable buffer (Tris) for making up the glutaraldehyde solution, 2) by use of an appropriate quenching agent (Triton X 100) and 3) by selection of a suitable imaging filter such as a TRITC 585-615 nm. A combination of the above three criteria gave the best results. Other techniques under investigation include glutaraldehyde concentration, incubation period, $\mathrm{pH}$ of buffer and use of different clearing agents. 